\title{
Study on the Effect of Wing Bud Chitin Metabolism and Its Developmental Network Genes in the Brown Planthopper, Nilaparvata lugens, by Knockdown of TRE Gene
}

\section{OPEN ACCESS}

Edited by:

Senthil-Nathan Sengottayan,

Manonmaniam Sundaranar University,

India

Reviewed by:

Wen-Jia Yang,

Guiyang University, China

Pin-Jun Wan,

China National Rice Research Institute

(CAAS), China

*Correspondence:

Bin Tang

tbzm611@yahoo.com;

tbzm611@hznu.edu.cn

${ }^{\dagger}$ These authors have contributed equally to this work.

Specialty section:

This article was submitted to Invertebrate Physiology,

a section of the journal

Frontiers in Physiology

Received: 26 June 2017 Accepted: 14 September 2017

Published: 26 September 2017

Citation:

Zhang L, Qiu L-Y, Yang H-L, Wang H-J, Zhou M, Wang S-G and Tang B (2017) Study on the Effect of Wing Bud Chitin Metabolism and Its Developmental Network Genes in the

Brown Planthopper, Nilaparvata lugens, by Knockdown of TRE Gene.

Front. Physiol. 8:750

doi: 10.3389/fphys.2017.00750

\section{Lu Zhang ${ }^{\dagger}$, Ling-Yu Qiu ${ }^{\dagger}$, Hui-Li Yang, Hui-Juan Wang, Min Zhou, Shi-Gui Wang and Bin Tang*}

Hangzhou Key Laboratory of Animal Adaptation and Evolution, College of Life and Environmental Sciences, Hangzhou Normal University, Hangzhou, China

The brown planthopper, Nilaparvata lugens is one of the most serious pests of rice, and there is so far no effective way to manage this pest. However, RNA interference not only can be used to study gene function, but also provide potential opportunities for novel pest management. The development of wing plays a key role in insect physiological activities and mainly involves chitin. Hence, the regulating role of trehalase (TRE) genes on wing bud formation has been studied by RNAi. In this paper, the activity levels of TRE and the contents of the two sugars trehalose and glucose were negatively correlated indicating the potential role of TRE in the molting process. In addition, NITRE1-1 and NITRE2 were expressed at higher levels in wing bud tissue than in other tissues, and abnormal molting and wing deformity or curling were noted $48 \mathrm{~h}$ after the insect was injected with any double-stranded TRE (dsTRE), even though different TREs have compensatory functions. The expression levels of NICHS1b, NICht1, NICht2, NICht6, NICht7, NICht8, NICht10, NIIDGF, and NIENGase decreased significantly $48 \mathrm{~h}$ after the insect was injected with a mixture of three kinds of dsTREs. Similarly, the TRE inhibitor validamycin can inhibit NICHS1 and NICht gene expression. However, the wing deformity was the result of the NIIDGF, NIENGase, NIAP, and NITSH genes being inhibited when a single dsTRE was injected. These results demonstrate that silencing of TRE gene expression can lead to wing deformities due to the down-regulation of the AP and TSH genes involved in wing development and that the TRE inhibitor validamycin can co-regulate chitin metabolism and the expression of wing development-related genes in wing bud tissue. The results provide a new approach for the prevention and management of N. lugens.

Keywords: Nilaparvata lugens, trehalase, wing bud, RNA interference, chitin synthase, chitinase

\section{INTRODUCTION}

Trehalose is widely distributed in insect tissues (including the epidermis and gut) and is the extracellular source of sugar for many insect species (Becker et al., 1996). Trehalose is known as the blood sugar of insects and plays a key role in various physiological processes (Kikuta et al., 2012; Yasugi et al., 2017). Trehalase (TRE), in insects, is divided into two 
types- soluble TRE, also called TRE1 or Treh1, and membranebound TRE, also called TRE2 or Treh2 (Shukla et al., 2015; Tang et al., 2016; Zhao et al., 2016). TRE1 is involved in the hydrolysis of endogenous trehalose, and TRE2 functions in the assimilation of exogenous trehalose as a carbon source (Becker et al., 1996; Chen et al., 2010a). Most insect species, including Spodoptera exigua (Tang et al., 2008; Chen et al., 2010a), Apis mellifera (Lee et al., 2007), Bombyx mori (Mitsumasu et al., 2005; Kamei et al., 2011), Laodelphax striatellus (Zhang et al., 2012), Omphisa fuscidentalis (Tatun et al., 2008a,b), and Bemisia tabaci (Wang et al., 2014) have one soluble TRE gene as well as one membranebound TRE gene (Bansal et al., 2013). In addition, some insect have more than one soluble TRE; two Treh1 were found in Leptinotarsa decemlineata (Shi J. F. et al., 2016), five Treh1 were found in Harmonia axyridis (Tang et al., 2014; Shi Z. K. et al., 2016) and four Treh1 were found in Tribolium castaneum (Tang et al., 2016). In addition, two TRE1 and one TRE2 have been cloned and reported in Nilaparvata lugens (Zhao et al., 2016). All of the different TREs can regulate and maintain trehalose balance during insect development and physiological processes.

Chitin is a major component of the exoskeleton, which includes the cuticle, leg, wing bud, feelers, and insect outside structure; it is also found in the internal structures of many insects and other arthropods, including the peritrophic matrix, inner cuticular linings of the alimentary canal, tracheal system, genital ducts, and ducts of the various dermal glands (Zhu et al., 2016). During insect development and metamorphosis, the chitin contents of the cuticle fluctuate as a complex function of the activities of chitin synthase A (CHS-A), which forms chitin via the chitin synthesis pathway; chitinase and chitinaselike (Cht), which degrade chitin to low-molecular-weight chitooligosaccharides; and $\beta-N$-acetylglucosaminidases (NAGs), which catalyze the stepwise removal of terminal, non-reducing $\beta$ $\mathrm{N}$-acetylglucosamine residues from chitooligosaccharides ( $\mathrm{Zhu}$ et al., 2016). In addition, that the chitin biosynthesis pathway is a well-established key target for pest control, and TRE is the first gene in this pathway (Tang et al., 2017). Previous studies have shown that target gene silencing via RNA interference (RNAi) or inhibition of TRE activities can lead to insect death or morphological defects because TRE plays an important regulatory role in chitin metabolism (Zhao et al., 2016; Tang et al., 2017). TRE regulates the expression of CHS and Cht in the insect cuticle and midgut, and inhibiting chitin biosynthesis kills pests when TRE gene expression is suppressed or knocked down (Chen et al., 2010a; Zhang et al., 2012; Tang et al., 2016, 2017; Zhao et al., 2016). When insect chitin synthesis or degradation malfunction or the chitin content are decreases, normal molting does not occur, and abnormalities are observed (Zhao et al., 2016; Zhang et al., 2017a).

When insects undergo molting, the cuticle of the exoskeleton is renewed by degrading the old chitin and cuticle proteins and synthesizing new ones (Deng et al., 2016). The wing development network includes many genes, of which EN (engrailed), TSH (teashirt), WG (wingless), DLL (distal-less), VG (vestigial), SC (scute), VVL (ventral veins lacking), CI (cubitus interruptus), and AP (apterous) play important roles (Xue et al., 2013,
2014). Proper development of the wing in insects involves the coordinate action of several genes (Ramesh Kumar et al., 2016). There are three key regulatory genes involved in insect wing development: $W G, V G$, and $A P$; these genes were studied in two basalinsects (Niwa et al., 2010). Wing deformity was observed when double-stranded (ds) VG, dsAP, dsCI, and dsUBX (Ultrabithorax) were injected into N. lugens (Xue et al., 2014); wing deformity was also observed when a high level of validamycin was injected due to decreased expression of the $E N$, WG, SC, VVL, CI, and AP genes (Tang et al., 2017).

The selector gene AP plays a key role in the development of the Drosophila melanogaster wing because it governs the establishment of the dorsal-ventral (DV) compartment boundary (Bieli et al., 2015). Repression of TSH is important for the establishment of distal wing fate, as ectopic expression of TSH blocks $W G$ expression at the DV boundary and interferes with wing pouch development (Casares and Mann, 2000; Wu and Cohen, 2002). The homeobox gene DLL is a crucial transcription factor involved in limb development and is highly conserved among both vertebrates and invertebrates (Sunwoo et al., 2008; Pechmann et al., 2011; Plavicki et al., 2012). Different AP alleles can lead to a wide range of wing phenotypes (Stevens and Bryant, 1985), while loss of TSH gene expression can result in the fusion of the proximal structures of the wing and halteres to the thoracic cuticle (Soanes et al., 2001). Wings that are $\sim 39.5 \%$ curled were observed when the NIDLL gene was knockdown by the way of RNAi; RNAi could also lead to an abnormal phenotype in not only the wing, which was extremely small, but also the haltere, which was small and disrupted, and produce defects, for example, extraordinary bristles (Lin et al., 2014).

Rice is the most important cereal crop in the Asia-Pacific region. The brown planthopper $(\mathrm{BPH}), N$. lugens (Stål), a longdistance migration insect with wing dimorphism, is the most destructive rice pest in Asia. Macropterous adults have the ability to fly long distances and invade rice-growing areas, while brachypterous adults are adapted for reproduction and can produce numerous offspring in rice fields (Xue et al., 2013). RNAi has been used as a gene silencing strategy via the introduction of long dsRNA for pest control (Liu et al., 2010, 2015; Wang et al., 2012, 2013; Zhao et al., 2016; Li et al., 2017). In previous studies, we found that $N$. lugens could not complete the molting process and observed an abnormal phenotype when the expression of the three TRE genes was knocked down by RNAi (Zhao et al., 2016) or when TRE activities were inhibited by the TRE inhibitor validamycin (Tang et al., 2017). And it is known that TRE participate and regulates both homeostasis and development (Thompson, 2003; Tatun et al., 2008a,b; Shukla et al., 2015). Abnormal development, weight loss, reduced chitin synthesis, decreased chitin content, hampered growth, decreased flight capacity, and lethal metamorphosis are found when TRE activity is inhibited (Shukla et al., 2015; Shi J. F. et al., 2016; Tang et al., 2017; Zhang et al., 2017b). These results indicated that insect chitin synthesis or degradation was severely affected and that insect chitin decreased when TRE gene expression or protein activities were inhibited (Zhang et al., 2017b). From the previous studies, TRE genes play a key role in the wing development and by the way of wing-related genes expression. However, it is not clear 
how TRE regulates wing development. Therefore, the present study aimed to further investigate the functions of TRE and validamycin in $N$. lugens wing development by evaluating gene expression patterns when different TRE genes or TRE activities are inhibited. In other words, the potential mechanism was elucidated for trehalase as an effective target for the control of N. lugens.

\section{MATERIALS AND METHODS}

\section{Insects}

The BPHs used in this study were from the China National Rice Research Institute (Hangzhou, China), and all rice cultivars were infected with TN1 (Taichung Native 1). The experimental insects were reared on fresh TN1 rice in an artificial climate chamber or in an artificial climate chamber at $25 \pm 1^{\circ} \mathrm{C}$, $(70 \pm 5) \%$ relative humidity, and $14 \mathrm{~L}: 10 \mathrm{D}$ photoperiod. All experiments were performed under the same conditions. At each molt, developmental stages were synchronized by collecting new nymph, pupae, or adults. The insects used for the microinjection of RNAi were BPHs on the first day of the 5th instar nymph.

\section{Trehalase Activities Detected during Different Developmental Stages}

An experimental population was used in this trial. Insects were subjected to soluble and membrane-bound TRE activity analyses at different stages from the beginning of the 5 th instar until $72 \mathrm{~h}$ of the adults. In this experiment, several insects' whole body (about 5-10 insects) at the same developmental stage were used to detect TRE activity, trehalose, and glycogen contents every $12 \mathrm{~h}$ and was replicated three times.

TRE activity assays were conducted according to the earlier methods with some modifications (Tatun et al., 2008a,b). Briefly, insects were homogenized in phosphate buffer ( $\mathrm{pH}$ 7.0; Sangon Biotech, China) and the homogenate was centrifuged at 1,000 g for $20 \mathrm{~min}$ at $4^{\circ} \mathrm{C}$. Subsequently, $350 \mu \mathrm{l}$ of the supernatant was removed and ultracentrifuged at $20,800 \mathrm{~g}$ for $60 \mathrm{~min}$ at $4^{\circ} \mathrm{C}$. The remaining supernatant was used to determine the protein, trehalose, and glycogen concentrations as described below. The supernatant obtained from ultracentrifugation was used to determine TRE1 activity, while the sediment was resuspended in phosphate buffer ( $\mathrm{pH}$ 7.0) and used to evaluate TRE2 activity. The protein and glucose concentrations in both the supernatant and sediment fractions were determined. To investigate TRE activity, the supernatantor suspension obtained from ultracentrifugation $(60 \mu \mathrm{l})$ was uniformly mixed with 75 $\mu \mathrm{l}$ of $40 \mathrm{mM}$ trehalose (Sigma-Aldrich, USA) and $165 \mu \mathrm{l}$ of phosphate buffer ( $\mathrm{pH} 7.0$ ). The mixture was then incubated at $37^{\circ} \mathrm{C}$ for $60 \mathrm{~min}$ and centrifuged at $12,000 \mathrm{~g}$ for $10 \mathrm{~min}$ at $4^{\circ} \mathrm{C}$. The resulting supernatants $(50 \mu \mathrm{l})$ were used to measure TRE activity using the Glucose (Go) Assay Kit (SigmaAldrich) according to the manufacturer's instructions. The protein concentration was determined using the BCA Protein Assay Kit (Beyotime, China) according to the manufacturer's instruction.

\section{Trehalose and Glycogen Assays during Different Developmental Stages}

The trehalose content assay was conducted according to the earlier method with some modifications (Leyva et al., 2008). The trehalose content was measured in $10 \mu \mathrm{l}$ of the supernatant described above using anthrone. The reagent was prepared by dissolving $0.1 \mathrm{~g}$ of anthrone (Sinopharm, China) in $100 \mathrm{ml}$ of concentrated sulfuricacid ( $98 \%$; Sinopharm), kept protected from light, and used within $12 \mathrm{~h}$. To measure the trehalose content, $10 \mu \mathrm{l}$ of $1 \%$ sulfuric acid was added to $10 \mu \mathrm{l}$ of sample and mixed uniformly. The obtained mixture was incubated at $90^{\circ} \mathrm{C}$ for $10 \mathrm{~min}$ and then cooled at $0^{\circ} \mathrm{C}$ for $3 \mathrm{~min}$. In the second step, $10 \mu \mathrm{l}$ of $30 \%$ potassium hydroxide (Sinopharm) solution was added to the sample and mixed uniformly. The obtained mixture was incubated at $90^{\circ} \mathrm{C}$ for $10 \mathrm{~min}$ and then cooled at $0^{\circ} \mathrm{C}$ for $3 \mathrm{~min}$. In the final step, $200 \mu \mathrm{l}$ of anthrone reagent was added to the sample and mixed uniformly. The obtained mixture was incubated at $90^{\circ} \mathrm{C}$ for $10 \mathrm{~min}$ and then cooled at $0^{\circ} \mathrm{C}$, and the absorbance was read at $620 \mathrm{~nm}$. To determine the glycogen concentration, another $10-\mu \mathrm{l}$ aliquot of the supernatant described in the previous section was incubated at $40^{\circ} \mathrm{C}$ for $4 \mathrm{~h}$ in the presence of starch glycosidase enzymes (Sigma-Aldrich) to hydrolyze glycogen into glucose. The glucose content was determined using the glucose (Go) Assay Kit according to the manufacturer's instructions.

\section{Total RNA Isolation and Expression Studies}

In the experiment of TRE genes expression pattern, the different tissues including head, leg, wing bud, cuticle, and fat body, from about 30 to 50 individuals were used. Three replicate samples of all the tissues were used to extract total RNA by using TRIzol (Invitrogen, Carlsbad, California, USA), respectively. The expression of three TRE genes in the head, leg, wing bud, cuticle, and fat body of $N$. lugens were detected by qRT-PCR.

In the RNAi experiments, total RNA was extracted from the wing bud of $N$. lugens using TRIzol (Invitrogen, Carlsbad, California, USA) following the manufacturer's instructions. The total RNA integrity was determined by $1 \%$ agarose gels electrophoresis, and the RNA concentration and purity were measured using a Nanodrop 2000 spectrophotometer (Thermo Fisher Scientific, Waltham, MA, USA). First-strand cDNA synthesis was performed using the Prime Script ${ }^{\circledR} \mathrm{RT}$ reagent Kit With gDNA Eraser (Takara, Kyoto, Japan) and stored at $-20^{\circ} \mathrm{C}$.

Complementary DNA synthesis and quantitative real-time polymerase chain reaction (qRT-PCR) were performed to analyze the distribution of NlTRE1-1, NITRE1-2, and NITRE2 using gene-specific primers (Table 1). Using $1 \mathrm{mg}$ of total RNA as a template and a specifically designed Nl-18S primer pair (Table $\mathbf{1}$ ), the stability of $18 \mathrm{~S}$ RNA was demonstrated by PCR performed under the following conditions: $95^{\circ} \mathrm{C}$ for $5 \mathrm{~min}, 28$ cycles at $95^{\circ} \mathrm{C}$ for $30 \mathrm{~s}, 60^{\circ} \mathrm{C}$ for $30 \mathrm{~s}$, and $72^{\circ} \mathrm{C}$ for $30 \mathrm{~s}$, followed by a final extension at $72^{\circ} \mathrm{C}$ for $10 \mathrm{~min}$. The relative mRNA expression levels of unique genes were assessed via qRT-PCR with a SYBR Green master mix (SYBR Green Premix Ex Taq, Takara, Japan) in a Bio-Rad CFX96TM Real-Time PCR Detection System (Bio-Rad Laboratories Inc., Hercules, CA, USA). Production of the standard and melting curves confirmed the specificity and 
TABLE 1 | The primers of three trehalase and 185 gene for qRT-PCR.

\begin{tabular}{|c|c|c|c|c|}
\hline Gene & GenBank number & Forward $\left(5^{\prime}-3^{\prime}\right)$ & Reverse $\left(5^{\prime}-3^{\prime}\right)$ & Length of target fragment (bp) \\
\hline NITRE1-1 & FJ790319 & GCCATTGTGGACAGGGTG & CGGTATGAACGAATAGAGCC & 132 \\
\hline NITRE1-2 & KU556829 & GATCGCACGGATGTTA & AATGGCGTTCAAGTCAA & 178 \\
\hline NITRE2 & GQ397451 & TCACGGTTGTCCAAGTCT & TGTTCGTTCGGCTGT & 197 \\
\hline NI-18S & - & CGCTACTACCGATTGAA & GGAAACCTTGTTACGACTT & 165 \\
\hline
\end{tabular}

accuracy of the primers. All primers were designed to determine the expression levels of the corresponding homologous genes of the trehalose and chitin metabolism pathways (Zhang et al., 2011; Tang et al., 2017), including the following: three TREs, CHS1 and its transcripts CHS1a and CHS1b (Wang et al., 2012), 10 Chts, endo- $\beta$-N-acetylglucosaminidase (ENGase), and imaginal disc growth factor (IDGF) (Table 3, Xi et al., 2015b). Additionally, the relative expression levels of wing development network-related genes were detected via qRT-PCR, including the following: $E N$, TSH, WG, DLL, VG, SC, VVL, CI, and AP (Table 4, Tang et al., 2017).

Each PCR was performed in a $20-\mu l$ volume, including $1 \mu l$ of each primer, $10 \mu \mathrm{l}$ of SYBR buffer, $7 \mu l$ of ultrapure water, and 1 $\mu l$ of cDNA. The qRT-PCR experiment was performed according to this cycling regime: preincubation at $95^{\circ} \mathrm{C}$ for $3 \mathrm{~min}, 35$ cycles of $95^{\circ} \mathrm{C}$ for $10 \mathrm{~min}$ and $60^{\circ} \mathrm{C}$ for $30 \mathrm{~s}$. The amplification of $18 \mathrm{~S}$ $R N A$ was quantified as an internal control. After amplification, a melting curve analysis was performed in triplicate, and the results were averaged. The values were calculated using three independent biological samples, and the $2^{-\Delta \Delta \mathrm{CT}}$ method was used for the analysis of relative gene expression (Livak and Schmittgen, 2001).

\section{dsRNA Synthesis and Injections}

Using $N$. lugens cDNA template and specific primers containing the T7 promoter sequence at their 5' ends (Table 2), regions of three NITRE genes were amplified by RT-PCR. The profile used in the reactions included 40 cycles of $95^{\circ} \mathrm{C}$ for $30 \mathrm{~s}, 58^{\circ} \mathrm{C}$ for $30 \mathrm{~s}$, and $72^{\circ} \mathrm{C}$ for $45 \mathrm{~s}$ and a final extension at $72^{\circ} \mathrm{C}$ for 10 min. Purified TRE amplicons were transcribed in vitro to synthesize dsRNA using the T7 RiboMAX Express RNAi System (Promega Corporation, Madison, USA) (Zhao et al., 2016). A green fluorescence protein (GFP) amplicon was used as the control. Sense and anti-sense strands were first produced in two separate transcription procedures and then mixed for annealing. Reactions were incubated for $10 \mathrm{~min}$ at $70^{\circ} \mathrm{C}$ and then placed on an ice bath for $20 \mathrm{~min}$. Finally, dsRNAs were precipitated with $95 \%$ ethanol and $3 \mathrm{M}$ sodium acetate ( $\mathrm{pH}$ 5.2), washed with $70 \%$ ethanol, air dried, and resuspended. The integrity and quantity of dsRNAs were evaluated by spectroscopy with Nanodrop 2000 (Thermo Fisher Scientific) and by agarose gel electrophoresis.

Using an IM-31 microinjector (NARISHIGE, JAPAN), dsTRE1-1, dsTRE1-2, dsTRE2, mixture of dsTRE1-1 and dsTRE12 mixture, and mixture of three dsTREs (200 ng of each) were injected into the abdomen of the $N$. lugens nymph. Control groups were injected with $d s G F P$ or with $100 \mathrm{nl}(10 \mu \mathrm{g} / \mu \mathrm{l}$ and $1 \mu \mathrm{g}$ of each insect) of validamycin. Validamycin (C178990, Lot: 20306) is a specific trehalase inhibitor. It was obtained from Dr. Ehrenxtorfer and prepared in Germany. The efficiency of gene
TABLE 2 | Primers used for double stranded RNA synthesis.

\begin{tabular}{ll}
\hline Primer name & Primer sequence $\left(\mathbf{5}^{\prime} \mathbf{- 3}^{\prime} \mathbf{)}\right.$ \\
\hline DSNITRE1-1-F & GATGCAATCAAGGAGGTGTATGGC \\
DSNITRE1-1-R & CGTATTCACCTCCACCTCCGT \\
DSNITRE1-1-FT & T7-GATGCAATCAAGGAGGTGTATGGC \\
DSNITRE1-1-RT & T7-CGTATTCACCTCCACCTCCGT \\
DSNITRE1-2-F & AGATGAAGGCATGTGGTTCG \\
DSNITRE1-2-R & CATCGATCGCCAACTGGTAAGC \\
DSNITRE1-2-FT & T7-AGATGAAGGCATGTGGTCG \\
DSNITRE1-2-RT & T7-CATCGATCGCCAACTGGTAAGC \\
DSNITRE2-F & CCAACTGCTATGACACCGACAAG \\
DSNITRE2-R & GGGTTCAGATCCTGCCGTCGCT \\
DSNITRE2-FT & T7-CCAACTGCTATGACACCGACAAG \\
DSNITRE2-RT & T7-GGGTCAGATCCTGCCGTCGCT \\
DSNIGFP-F & AAGGGCGAGGAGCTGTCACCG \\
DSNIGFP-R & CAGCAGGACCATGTGATCGCGC \\
DSNIGFP-FT & T7-AAGGGCGAGGAGCTGTTCACCG \\
DSNIGFP-RT & T7-CAGCAGGACCATGTGATCGCGC \\
\hline
\end{tabular}

T7 sequence: GGATCCTAATACGACTCACTATAGG.

knockdown resulting from RNAi was calculated as the ratio of gene expression between insects injected with target dsRNAs and GFP dsRNA, determined at $48 \mathrm{~h}$ after injection.

\section{Sample Collection, Phenotype Observations, and Photography}

DsRNA was injected into fifth-instar larvae of $N$. lugens, every $12 \mathrm{~h}$ after dsRNA injections, dead individuals (assumed to be caused by physical damage due to injection) were identified and discarded. The remaining treated insects were grouped into three replicates (exceed 30 nymphs each group). In addition, the wing tissues of other abnormal insects were collected $48 \mathrm{~h}$ after RNAi treatment for subsequent analysis of the expression of TRE, chitin metabolism-, and wing development-related genes by qRT-PCR. Photographs were taken of abnormal insects, especially those with deformed wing development, as well as of insects in the different dsRNA injection treatments.

\section{Statistical Analyses}

The statistical significance of differences in trehalase activities, trehalose, and glycogen contents were determined by one-way analysis of variance (ANOVA) and analyzed by Tukey's test. Comparisons of different developmental were made with a two-way (ANOVA) followed by Tukey's test. The significance level was set at $\alpha=0.05$.

As controls, the mRNA expression levels were designated in the non-injected and dsGFP-injected groups. In this study, 
TABLE 3 | Primers used for qRT-PCR measurements of chitin metabolism genes.

\begin{tabular}{|c|c|c|c|c|}
\hline Gene & GenBank number & Forward $\left(5^{\prime}-3^{\prime}\right)$ & Reverse $\left(5^{\prime}-3^{\prime}\right)$ & Length of target fragment (bp) \\
\hline NICHS1 & AEL88648 & CCGCAAACGATTCCTACAGA & AGGTCCTTGACGCTCATTCC & 222 \\
\hline NICHS1a & JQ040014 & TGTTCTTGCTACAACTCAATAAA & ACACCAATCCGATAGGCTC & 141 \\
\hline $\mathrm{NICHSb}$ & JQ040013 & GCTGTCTITGCTITCTCAT & ACACCAATCCGATAGGCTC & 187 \\
\hline NICht1 & AJO25036 & AGGTGGTTAGGGACGAGGAG & TGCGCTTGACATAGTTGGACT & 114 \\
\hline NICht2 & AJO25037 & GCAGATTTCTGGACAGGGAA & TGACGCACAAGCGGGAAG & 226 \\
\hline NICht3 & AJO25038 & CTACACCTCTGGCTAAACTCGG & AACTTGTCCTTGCGGCTGAT & 235 \\
\hline NICht4 & AJO25039 & TTGAGGAGGTTCACGGGTCT & CCTTACTGGAAACGAGGTTGG & 112 \\
\hline NICht5 & AJO25040 & AAAGCGTTCGTGATGAAATAGC & GATCCTITGCCTCAATCCAAT & 183 \\
\hline NICht6 & AJO25041 & GCTGGTAAGGAGATGCTATTCG & GTGGTTCTAAGGCTGGCTGTC & 155 \\
\hline NICht7 & AJO25042 & CTACTCTGCCATCCCATTCCT & GTCTGGGTITCTTCACTTCCTG & 161 \\
\hline NICht8 & AJO25043 & GAACAAAGTGCAAACTCAGTC & C CACCTTCTGTGGCTTCTGG & 106 \\
\hline NICht9 & AJO25044 & GTGCGGTATTGGTTGAAGAGG & GGTATAACGTGATTCCGAGCC & 147 \\
\hline NICht10 & AJO25045 & CAAGCCAATACCCAACAAAC & ACAGCAAATCCATAGAGCACA & 177 \\
\hline IDGF & AJO25056 & AAAAGAACGAGGAGGAGGG & TTGCTTGAGGATGGGGTAC & 170 \\
\hline ENGase & AJO25057 & TGTGGCAAGACTTCGTTA & ATGGGAGGGTTGGGATAG & 282 \\
\hline
\end{tabular}

TABLE 4 | Primers used for qRT-PCR measurements of wing development network genes.

\begin{tabular}{|c|c|c|c|}
\hline Gene & BPH ID & Forward $\left(5^{\prime}-3^{\prime}\right)$ & Reverse $\left(5^{\prime}-3^{\prime}\right)$ \\
\hline NIEN & NLU020829.1 & СTCACCTCCAGAAATGC & CTTCAGGCGAGACAGC \\
\hline NITSH & NLU025765.1 & TGGTAGGAGGAGACAAA & TTCCAGCAGAATGGAGT \\
\hline NIWG & NLU010606.1 & $\begin{array}{l}\text { ATAACCTGCTACCCT } \\
\text { TGTCA }\end{array}$ & GTTCCACCTCCTGTITCTG \\
\hline NIDLL & NLU020890.1 & CGTACCACCCTTACCAGC & TTGCCTITGCCATTGTT \\
\hline NIWL & NLU013430.1 & GCTCCTGTCGTCTCCTCA & CGGGTGTTGGTGGTTGT \\
\hline $\mathrm{NICl}$ & NLU023528.1 & ACGGGAGGTGGTGGATT & CTGACATTGGAGTCGCTGA \\
\hline NIVG & NLU025618.1 & $\begin{array}{l}\text { AGCAACTACCAGAGC } \\
\text { ACCAA }\end{array}$ & AGCAACAGGCTGCCATAC \\
\hline NISC & NLU020108.1 & $\begin{array}{l}\text { GCAAGCGGAGAATC } \\
\text { AGTIT }\end{array}$ & GTCACCGACACGGGGATG \\
\hline NIAP & NLU018087.2 & TGGAGGTGGCGTTGGC & GCGTCAGGGTTATGGTTG \\
\hline
\end{tabular}

all data obtained were analyzed through one-way analysis of variance (ANOVA) and presented as the means \pm standard errors (SEs) of 3-6 biological replicates. In Duncan's new multiple range test, a $P$-value below 0.01 or 0.05 was considered extremely significant or significant, respectively. A double asterisk indicates a highly significant difference in mRNA levels between each of the dsNlTRE-injected groups and the dsGFP group measured at the same time $(P<0.01, T$-test $)$, and an asterisk or different capital letter indicates a significant difference $(P<0.05, T$-test $)$.

\section{RESULTS}

\section{Analysis of Trehalase Activity and the Concentrations of Trehalose and Glycogen during the Different Developmental Stages}

The activity level of TRE1 remained relatively low during the molting process and was higher after molting (Figure 1A). The TRE1 activity increased from 0 to $24 \mathrm{~h}$, decreased from 24 to $48 \mathrm{~h}$, and remained relatively higher 60 and $72 \mathrm{~h}$ after the stage of the 5th instar nymph. In addition, TRE1 activity increased in the first stage until $36 \mathrm{~h}$ and then decreased from 36 to $72 \mathrm{~h}$ in the adult stage. TRE2 activity was lower in the 5th instar nymph and higher in adults (Figure 1B).

The contents of trehalose and glycogen changed during the molting process. The contents of these two sugars decreased from the 5th instar nymph middle stage to the molting staged and then increased. The trehalose content remained at the lowest level when molting completed at $0 \mathrm{~h}$ of adulthood, at $0.0200 \pm 0.008$ $\mathrm{nmol} \mu \mathrm{g}^{-1}$ protein, and remained low from 12 to $36 \mathrm{~h}$ in the adult stages (Figure 1C); in contrast, the activities of TRE1 and TRE2 increased (Figures 1A,B). However, the glycogen content was low at 72 and $84 \mathrm{~h}$ in the 5th instar stage and then increased during the adult stages (Figure 1D).

\section{Expression of Trehalase Genes in Different Tissues}

According to the qRT-PCR results, NITRE1-1 and NlTRE2 had similar trends in mRNA expression but different levels of gene expression among the five tissues: head, leg, wing bud, cuticle, and fat body. As shown in Figure 2, the highest expression of both genes was registered in wing bud tissues, followed by leg and head tissues, and the lowest in cuticle and fat body tissues. The quantitative analysis of the expression of the three NITRE genes in the different tissues used the expression values obtained in head tissues as the controls. The expression level of NITRE1-2 was relatively higher in the head and wing bud tissues than in the other tissues (Figure 2). Overall, the results showed that three NITRE genes were differentially expressed across the several tissues analyzed and that their expression was significantly higher in the wing bud tissues of the BPH, followed by head tissues.

\section{Expression of Trehalase Genes in Wing Bud Tissue and the Observation of Wing Variation after RNA Interference}

In the previous studies, different presage of molting or wing deformities have been detected when TRE genes were 

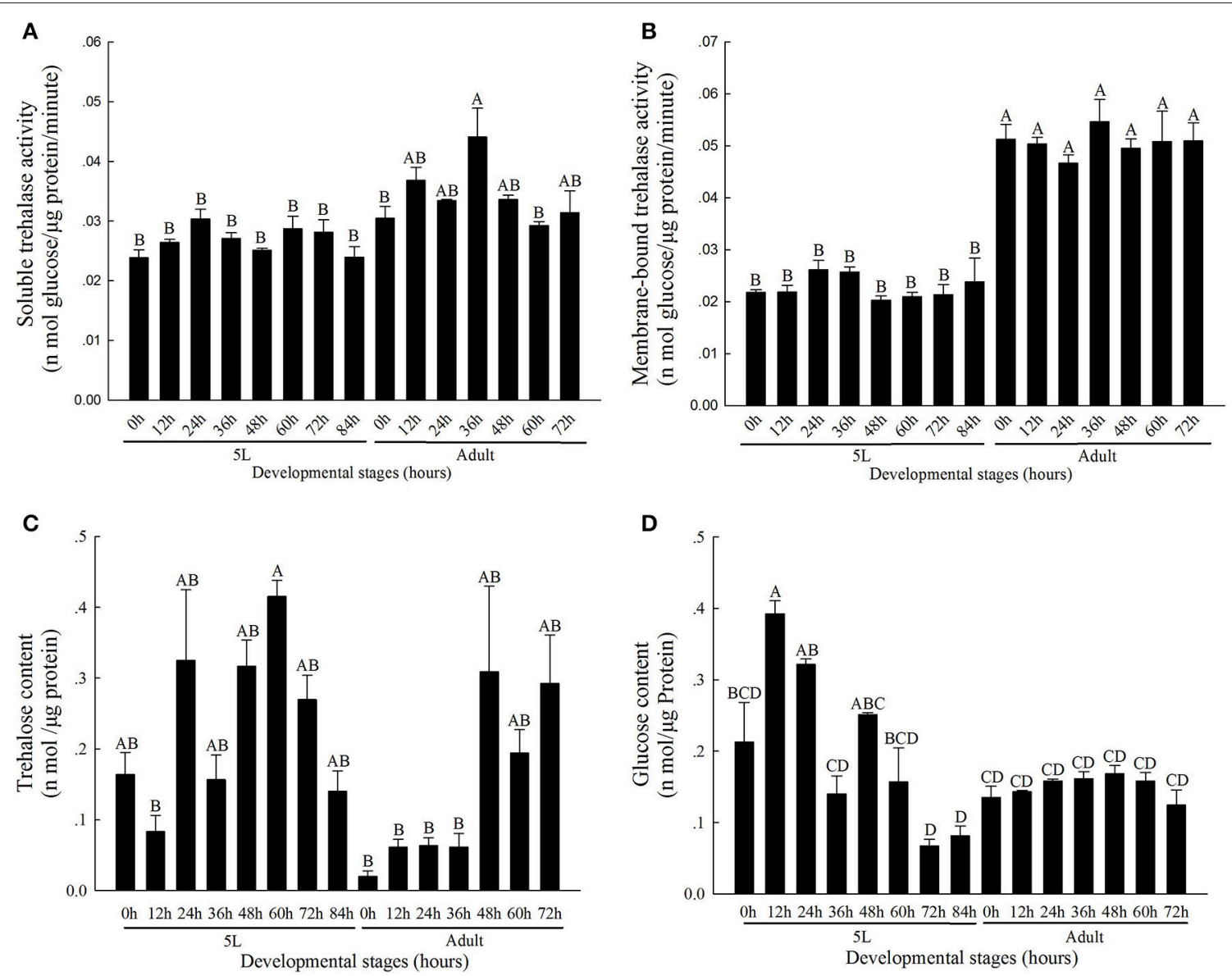

FIGURE 1 | Soluble trehalase (A), Membrane-bound trehalase activity (B), and trehalose (C), and glucose (D) levels in N. Iugens at different developmental stages from $0 \mathrm{~h}$ in 5 th instar nymph to $72 \mathrm{~h}$ in adults. All of $\mathrm{N}$. lugens 5 th instar nymph and adults were selected every $12 \mathrm{~h}$, and insects were collected and used to detect the activities of the two kinds of trehalase isoenzymes and measure the trehalose and glucose levels. Every group had three to five replicates. The age of the brown planthoppers was defined as follows: 5L-0, $0 \mathrm{~h}$ fifth-instar nymph; 5L-12, $12 \mathrm{~h}$ fifth-instar nymph; $5 \mathrm{~L}-24,24 \mathrm{~h}$ fifth-instar nymph; $5 \mathrm{~L}-36,36 \mathrm{~h}$ fifth-instar nymph; $5 \mathrm{~L}-48$ 48 h fifth-instar nymph; 5L-60, $60 \mathrm{~h}$ fifth-instar nymph; 5L-72, $72 \mathrm{~h}$ fifth-instar nymph; 5L-84, $84 \mathrm{~h}$ fifth-instar nymph; A-0, $0 \mathrm{~h}$ adults; A-12, $12 \mathrm{~h}$ adults; A-24, 24 h adults; A-36, $36 \mathrm{~h}$ adults; A-48, 48 h adults; A-60, $60 \mathrm{~h}$ adults; and A-72, $72 \mathrm{~h}$ adults. (Tukey's test, $\alpha=0.05, \mathrm{~A}>\mathrm{B}>\mathrm{C}>\mathrm{D}$ ).

knockdown by the way of RNAi or trehalase inhibitor of validamycin (Zhao et al., 2016; Tang et al., 2017). The injection of dsRNA from a single TRE gene could effectively inhibit the expression of the same gene at $48 \mathrm{~h}$ (Figure 3). An extreme decrease in NITRE1-1 and NITRE2 expression was registered $48 \mathrm{~h}$ after $d s T R E s$ injection $(P<0.01)$, which indicates that the mixture of $d s T R E s$ could effectively inhibit the expression of these two genes at $48 \mathrm{~h}$. NITRE1-1 and NITRE2 expression levels increased significantly after validamycin injection, and the levels of NlTRE1-2 also increased but not significantly when comparing the validamycin-injection group with the dsGFP-injection group. However, NITRE1-2 expression increased significantly $(P<0.01)$ $48 \mathrm{~h}$ after dsTRE2 injection (Figure 3B). With the successful silencing of the three NlTRE genes, the insects subjected to RNAi exhibited high mortality rates and presented various abnormal phenotypes compared with the control insects. Importantly, many insects did not complete wing development and presented an abnormal wing phenotype (Figure 3D).

\section{Chitin Synthase Gene Expression in Wing Bud Tissue after Knocking Down Three TRE Genes}

Chitin is the main component of the insect cuticle, trachea, and peritrophic membrane of the mid-gut (Zhu et al., 2016), and the wing bud is a part of the cuticle. The chitin content based on a mass ratio of w/w can reach up to $20 \%$ in normal insects. In addition, CHS is an essential gene in chitin biosynthesis during insect growth and development. N. lugens encodes only the CHS1 gene and two variable transcripts, CHS1a and CHS1b (Wang et al., 2012). The qRT-PCR results showed that NlCHS1 expression levels decreased significantly or extremely significantly $48 \mathrm{~h}$ after $d s T R E 1-1$ and validamycin injection and decreased after $d s T R E 1 s$ and $d s T R E s$ were injected (Figure 4A). NlCHS1a expression decreased significantly $48 \mathrm{~h}$ after $d s T R E 1-$ 1 and $d s T R E 2$ injection (Figure 4B), while NlCHS1a expression also decreased significantly after $d s T R E s$ and validamycin injection (Figure 4C). 


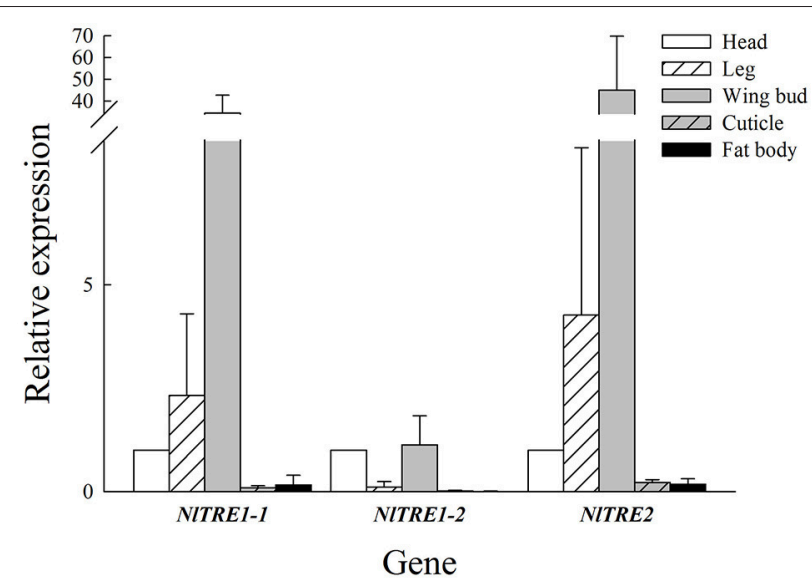

FIGURE 2 | Expression of NITRE1-1, NITRE1-2, and NITRE2 in the five different tissues of $N$. lugens analyzed. Total RNA was extracted from head, leg, wing bud, cuticle, and fat body tissues, and the expression of both genes was measured by quantitative real-time PCR using 18S RNA as the internal control. Values are the means \pm standard errors (SEs) from three independent measurements. The relative expression of each gene was determined in relation to that obtained in the head of $N$. lugens adults.

\section{Expression of Cht and Chitinase-Like Genes After dsTRE and Validamycin Injection}

The mRNA levels of Cht and chitinase-like genes, including 10 Chts, one IDGF, and one ENGase, after different dsTRE and validamycin injections were detected in wing bud tissue by qRT-PCR (Figure 5). The mRNA levels of Cht1 and IDGF decreased significantly $(P<0.05) 48 \mathrm{~h}$ after $d s$ TRE1-1 injection (Figures 5A,D); Cht3, Cht4, Cht6, Cht7, Cht10, and IDGF expression levels decreased significantly after validamycin injection, and Cht2, Cht6, Cht7, Cht8, Cht10, IDGF, and ENGase expression levels decreased significantly or extremely significantly $48 \mathrm{~h}$ after injection of a mixture of $d s T R E s$ (Figure 5). ENGase expression also decreased significantly after $d s T R E 1-2, d s T R E 2$, and $d s T R E 1 s$ were injected. The expression of IDGF also decreased extremely significantly $48 \mathrm{~h}$ after $d s T R E 1-2$ and $d s T R E 2$ injection (Figure 5D). Cht4 expression increased significantly $(P<0.05) 48 \mathrm{~h}$ after $d s$ TRE1-2 injection (Figure 5B); Cht5, Cht7, and Cht9 expression increased significantly or extremely significantly after $d s T R E 2$ injection; and Cht5 and Cht7 expression increased significantly after validamycin or $d s T R E 1 s$ injection, respectively (Figures 5B,C).

\section{The Expression of Genes Related to Wing Development after dsTRE and Validamycin Injection}

Moreover, the EN, TSH, WG, DLL, VG, SC, VVL, CI, and AP gene expression levels were also measured by qRT-PCR. The $V V L, C I$, and $A P$ gene expression levels decreased significantly after the injection of all different concentrations of validamycin (Tang et al., 2017), while those of VVL, AP, WG, VG, and $D L L$ also decreased after validamycin injection and did not differ significantly compared with those after dsGFP injection, except for the AP gene (Figure 6). The expression of the $A P$ gene decreased significantly after dsTRE1-1, dsTRE1-2, dsTRE2, $d s T R E s$, and validamycin injection (Figure 6A). In addition, the expression of TSH decreased significantly or extreme significantly after $d s T R E 1-1, d s T R E 2$, and $d s T R E 1 s$ were injected (Figure 6B). However, the expression levels of these genes, including $C I, V V L, E N, V G$, and $S C$, increased significantly $(P<$ 0.01 or $P<0.05)$ when $d s T R E 1-2$ or $d s T R E s$ were injected into $N$. lugens nymph (Figure 6), and $W G$ and $D L L$ also increased extreme significantly $(P<0.01)$ after $d s T R E 1-2$ was injected (Figures 6B,C).

\section{DISCUSSION}

Trehalose plays a key role at all developmental stages, including larvae, pupae, and adults (Becker et al., 1996; Elbein et al., 2003; Zhao et al., 2016). It not only can be degraded to glucose by two kinds of TRE but can also be synthesized by trehalose-6-phosphate synthase (TPS) and trehalose-6phosphate phosphatase (TPP) and released in the haemolymph (Tang et al., 2016; Yang et al., 2017) or converted to glycogen by glycogen synthase (GS) (Tang et al., 2012). Trehalose and glucose contents are relatively stable and are negatively correlated in the hemolymph (Tang et al., 2010). In addition, the contents of trehalose and glucose were negatively correlated from $72 \mathrm{~h}$ in 5 th instar nymph to $12 \mathrm{~h}$ in adults; this time period represents the molting process (Figures 1C,D). The contents of these two sugars were kept low through regulation by two kinds of TREs (Figures 1A,B). More trehalose was consumed or provided as energy during insect molting. In addition, the trehalose and glycogen contents and the activities of two TREs decreased significantly $48 \mathrm{~h}$ after $d s T R E 1-2, d s T R E 2$, and $d s T R E s$ were injected into N. lugens (Zhao et al., 2016; Zhang et al., 2017b). The glucose content also decreased $48 \mathrm{~h}$ after $d s T R E 1$ and $d s T R E 2$ were injected, and the trehalose content decreased $48 \mathrm{~h}$ after TRE2 was knocked down in S. exigua (Chen et al., 2010a). Insufficient trehalose during the molting process may prevent an insect from completing the chitin synthesis. Of course, more study is required to measure the amount of energy provided and ATP released when TRE or CHS and other chitin synthesis pathway genes are knocked down.

Insects can consume energy by degrading trehalose to glucose using TRE. Thus, many different insect tissues express TRE genes. TRE2 is expressed in the brain, cuticle and mid gut as detected by RT-PCR (Tang et al., 2008), while TRE1 and TRE2 expression has been detected in all tissues, including the mid gut, Malpighian tubules, and fat body in S. exigua and Apolygus lucorum (Chen et al., 2010a; Tan et al., 2014). TRE1 expression level is higher in the gut and lower in the integument, fat body, and embryo in Aphis glycines (Bansal et al., 2013). In our study, TRE1-1 and TRE2 expression could be detected in the head, leg, wing bud, cuticle, and fat body and was higher in head, leg, and wing bud tissues than in other tissue (Figure 2). In contrast, TRE1-2 was expressed in the head and wing bud but not in the other three tissues (Figure 2). Leg and wing bud 

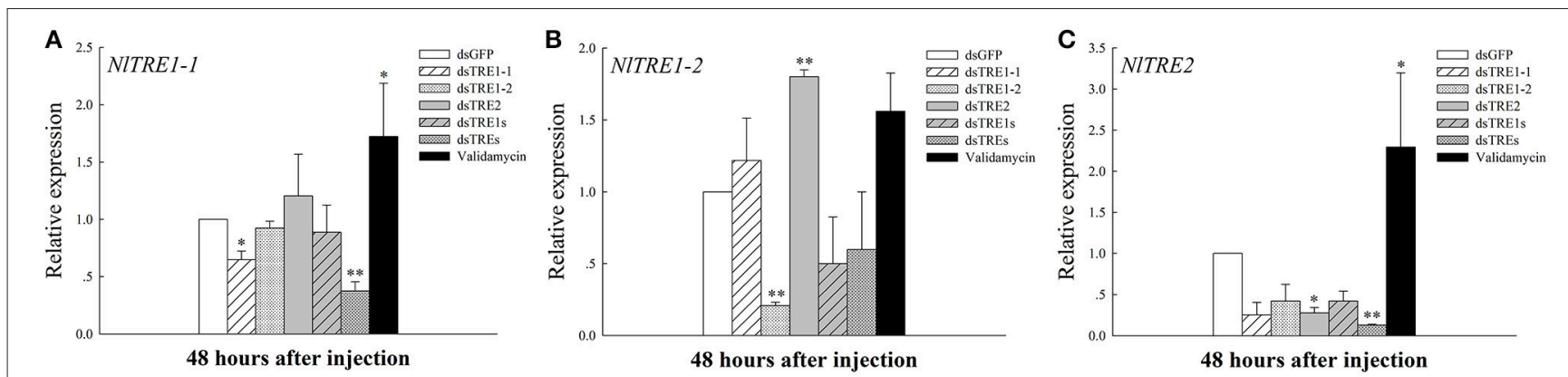

\section{D dsGFP}

dsTRE1-1

dsTRE1-2 dsTRE2

dsTRE1s

dsTREs

Validamycin

Short-winged Long-winged
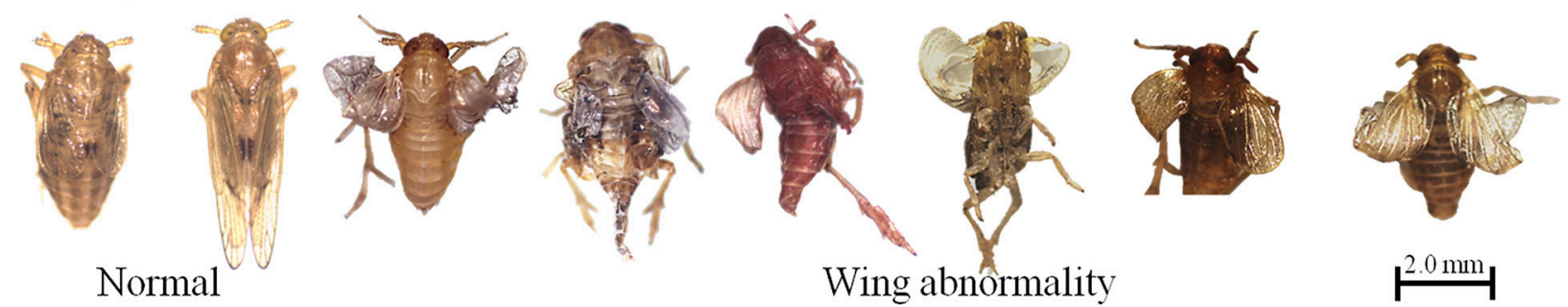

Wing abnormality

$2.0 \mathrm{~mm}$

FIGURE 3 | Changes in the mRNA transcript levels in wing bud and abnormal phenotypes of the three NITRE genes $48 \mathrm{~h}$ after injection with specific RNAi constructs and validamycin in N. lugens nymph. (A-C) Represent the mRNA levels of NITRE1-1, NITRE1-2, and NITRE2 after the injection of RNAi targeting the NITRE genes or validamycin normalized relative to the $\mathrm{Nl}-18 \mathrm{~S} \mathrm{mRNA}$ level. (D) Normal and different deformity phenotypes and wing curling. Last-instar nymphs were chosen as the targets for dsRNA injection. *indicated significant differences at $P<0.05$, and ${ }^{*}$ Indicated significant differences at $P<0.01$.
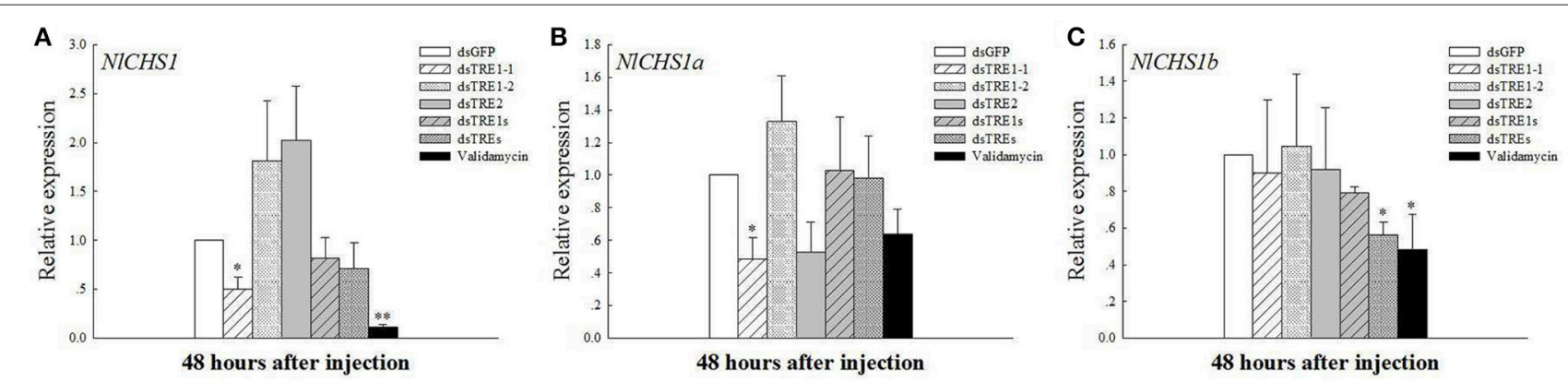

FIGURE 4 | Effects of different dsTRE or validamycin solutions on the relative expression levels of chitin synthase in wing bud tissue. And CHS1 (A), CHS1a (B), and $\mathrm{CHS1b}$ (C) genes' expression level at $48 \mathrm{~h}$ normalized relative to the $N L-18 \mathrm{~S}$ mRNA levels, as measured by qRT-PCR. ${ }^{*}$ Indicated significant differences at $P<0.05$, and ${ }^{* *}$ Indicated significant differences at $P<0.01$.

are components of the insect exoskeleton or cuticle, and the cuticle in our study did not include the leg or wing bud. The expression pattern of TRE genes in all kinds of tissues also differed during the different developmental stages (Tang et al., 2008; Chen et al., 2010a). The expression of other TRE genes may increase when one specific TRE gene is knocked down by RNAi (Chen et al., 2010a; Zhao et al., 2016; Zhang et al., 2017b); it is possible that similar genes have compensatory functions. The same phenomenon also observed in wing bud tissues, where NITRE1-2 expression increased significantly $48 \mathrm{~h}$ after $d s T R E 2$ was injected (Figure 3B), but NITRE2 expression decreased after
dsTRE1-1, dsTRE1-2, dsTRE2, dsTRE1s, or dsTREs was injected (Figure 3C, Zhang et al., 2017b).

Insects can present all kinds of abnormal phenotypes, including molting deformity and wing deformity, during the molting process, just as they can from the larvae to pupae or from nymph to adult stages (Chen et al., 2010a; Zhao et al., 2016; Zhang et al., 2017b). In N. lugens, about 25\% abnormal molting or wing deformity was observed when single of $d s T R E$ injected, and molting deformity or wing deformity are the main abnormal phenotypes, as well as the percentage is different according to the different dsTRE gene injection groups (Zhao et al., 2016). 

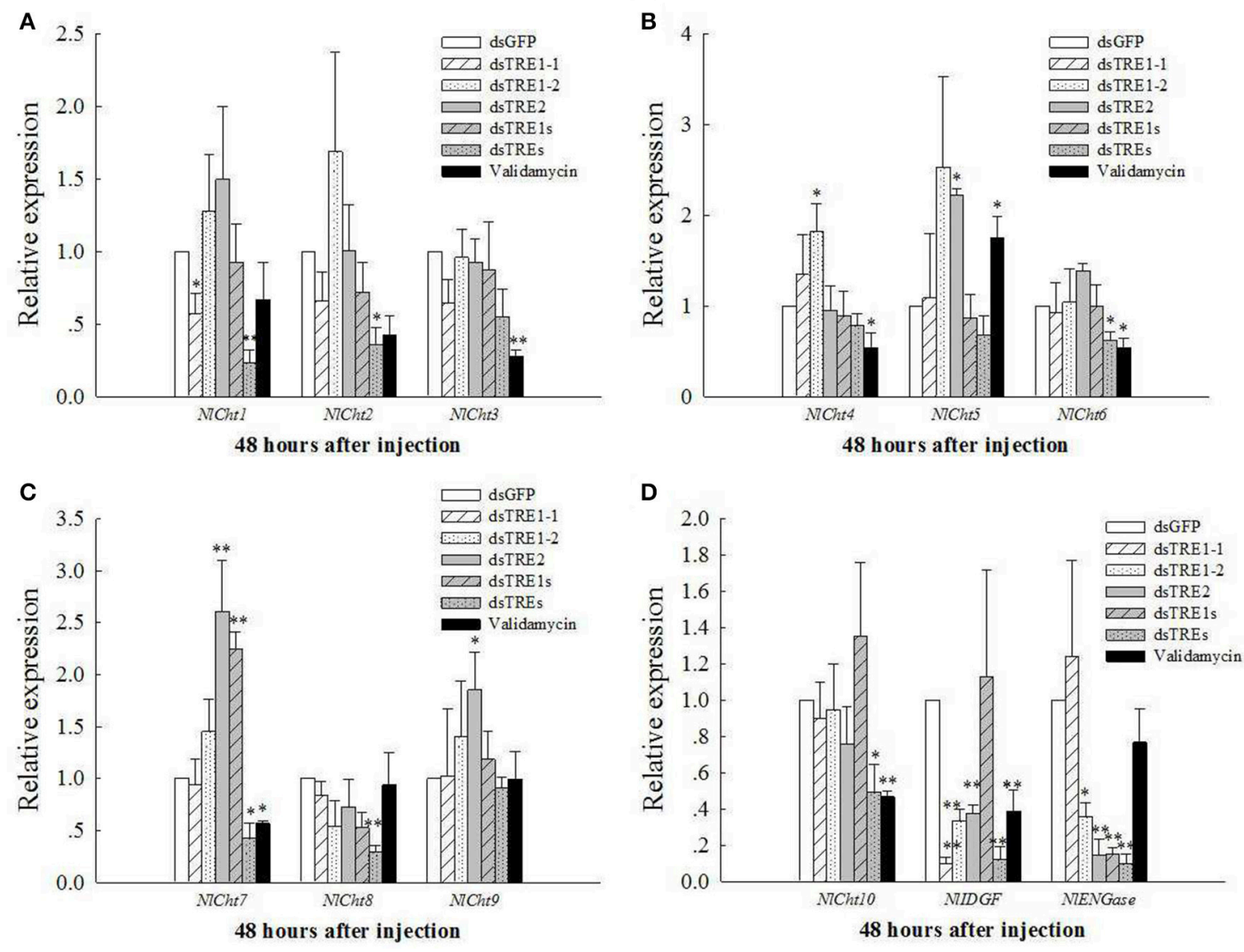

FIGURE 5 | Effects of dsTREs on the chitin degradation pathway in fifth-instar nymph at $48 \mathrm{~h}$. The mRNA levels of NICh1 to N/Cht3 (A), N/Ch4 to NICht6 (B), NICh7 to NICht9, (C) NICh10, one imaginal disc growth factor and one endo- $\beta$-N-acetylglucosaminidase (D) normalized relative to the N/-18S mRNA level as measured via qRT-PCR. ${ }^{*}$ Indicated significant differences at $P<0.05$, and ${ }^{*}$ indicated significant differences at $P<0.01$.
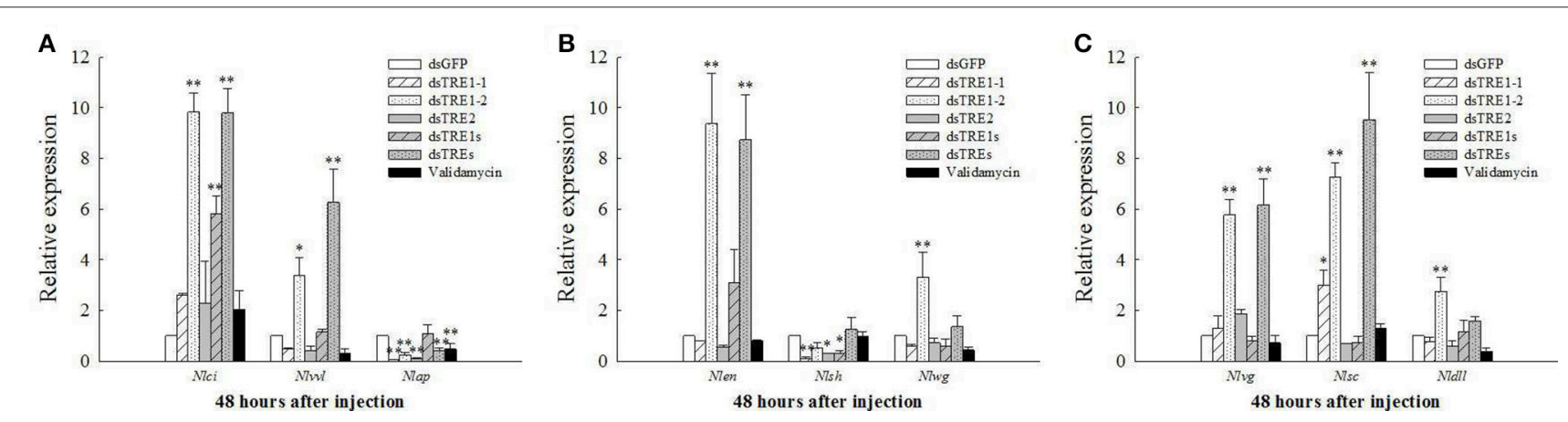

FIGURE 6 | Effects of different dsTRE or validamycin solutions on the relative expression levels of wing development network genes in wing bud tissue. It is including cubitus interruptus $(C l)$, ventral veins lacking $(W L L)$, apterous (AP), (A) engrailed (EN), teashirt (TSH), wingless (WG), (B) vestigial (VG), scute (SC) and distal-less (DLL), (C) at $48 \mathrm{~h}$ normalized relative to the $\mathrm{N}-18 \mathrm{~S}$ mRNA levels, as measured by qRT-PCR. ${ }^{*}$ Indicated significant differences at $P<0.05$, and ${ }^{* *}$ indicated significant differences at $P<0.01$.

Moreover, it exceeds $40 \%$ deformity and $60 \%$ mortality after injection $1 \mu \mathrm{g}$ trehalase inhibitor of validamycin into each larvae of $N$. lugens. And in the different abnormal phenotypes, most of insect were shown the molting and wing deformity (Tang et al.,
2017). In the same time, CHS1 $a$ and $C H S 1 b$ expression decreased 48 and $72 \mathrm{~h}$ after single or mixed $d s T R E s$ was injected and CHSA and CHSB expression also decreased 48 and $72 \mathrm{~h}$ after $d s T R E 1$ or dsTRE2 was injected in S. exigua (Chen et al., 2010a; Zhao et al., 
2016). N. lugens also presented wing deformities when single or mixed dsTREs was injected (Figure 3D), but CHS1, CHS1a, and $C H S 1 b$ together did not decrease in the wing bud tissues. In particular, CHS1, CHS1a, and CHS1b expression increased when $48 \mathrm{~h}$ after $d s T R E 1-2$ was injected (Figure 4 ). In addition, some insects do not undergo normal pupation when TREs or TPS genes are knocked down, and their larval weight and survival rate decrease significantly (Shi J. F. et al., 2016). These results suggest that insect deformity may be a common result of exoskeleton and chitin synthesis blocking, which was not the only reason for wing bud development, although the chitin content of total of $N$. lugens decreased significantly (Zhang et al., 2017b).

Some previous studies have reported that blocking trehalose metabolism, which includes TPS and TRE that regulate insect's chitin synthesis and degradation, prevents insects from completing their developmental and molting processes (Chen et al., 2010b,a; Zhao et al., 2016; Yang et al., 2017). These results indicate that the chitin synthesis pathway and chitinase gene as expression decrease regulated by trehalose metabolism-related genes (Ge et al., 2011; Tang et al., 2017) and that the chitin content decreases significantly $48 \mathrm{~h}$ after TRE knockdown or TRE inhibitor injection in N. lugens (Zhang et al., 2017b). We found that the expression of CHS1, CHS1a, and CHS1b changed slightly and that validamycin could inhibit $\mathrm{CHS} 1$ and $\mathrm{CHS} 1 \mathrm{~b}$ expression significantly (Figure 4). The expression of almost all Chts and chitinase-like genes, except Cht5, Cht8, and Cht9, as well as Cht3, Cht4, Cht6, Cht7, Cht10, and IDGF, in wing bud tissue decreased significantly $48 \mathrm{~h}$ after validamycin injection (Figure 5). These results show that validamycin can inhibit the activities of two kinds of TREs and lead to insect molting and wing deformities by affecting or regulating chitin synthesis and degradation in wing bud and cuticle or total tissues (Tang et al., 2017; Zhang et al., 2017b). The molting process of insects can be affected when the chitinase or CHS gene expression decreases (Zhu et al., 2008, 2016; Xi et al., 2015b), and the same kinds of deformities, including failure to break up the old cuticle during the molting process and wing deformity were found in this study. These results are similar to other observations that the expression of TPS, chitinase, TRE and CHS-or chitin synthesis pathway-related genes was knocked down. They also show that RNAi is effective for the pest management of $N$. lugens and other insects (Chen et al., 2008, 2010b,a; Zhu et al., 2008; Arakane et al., 2009; Xi et al., 2014, 2015a,b; Zhao et al., 2016; Yang et al., 2017; Zhang et al., 2017b).

Only IDGF and ENGase gene expression decreased when the TRE gene was knocked down, and the expression of many of the Chts and chitinase-like genes decreased in wing bud tissue $48 \mathrm{~h}$ after the injection of a mixture of $d s T R E s$ (Figure 5). When the expression of a number of wing development-related genes, including $E N, T S H, W G, D L L, V G, S C, V V L, C I, A P$, and UBX, is inhibited by RNAi or another method, insect wing abnormal phenotypes such as wing deformity (Figure 3D), small wings and curled wings are observed (Casares and Mann, 2000; Wu and Cohen, 2002; Lin et al., 2014; Xue et al., 2014; Tang et al., 2017). However, wing deformity is observed as a result of the knockdown of any TRE gene; wing development-related genes may be affected when different $d s T R E s$ are injected into wing bud tissue. We found that the AP or TSH gene' expression level decreased significantly after the injection of three single TRE dsRNAs or a mixture of $d s T R E 1 s$ and $d s T R E s$ (Figures 6A,B) and conclude that $A P$ or TSH gene silencing in wing bud tissue maybe the main reason for halted wing development or wing curling, as $A P$ and TSH are the most important genes and play a key role during the development of the D. melanogaster wing (Fasano et al., 1991; Bieli et al., 2015). Dorsoventral axis formation in the Drosophila wing depends on the activity of the selector gene AP (Milán and Cohen, 2000), which was found in two studies to be a key regulatory gene involved in insect wing development (Niwa et al., 2010), and the wing blade does not develop in AP mutants (Diaz-Benjumea and Cohen, 1993; Williams et al., 1993; Klein et al., 1998), The TSH gene is required for proper formation of the trunk segments within the developing embryo (Fasano et al., 1991). D. melanogaster is a complete metamorphosis insect, while $N$. lugens is an incomplete metamorphosis insect which has long-wing and short-wing types (Xue et al., 2014). For these two different kinds of insects, there may be some different proteins that are implicated in the development of wing and it needs to be further studied. Nevertheless, $N$. lugens wing deformity in wing bud tissue may be due to lower expression of the AP and TSH genes when the TRE gene is knocked down. TRE can regulate the chitin metabolism pathway to control the molting process and balance the chitin content (Zhao et al., 2016; Tang et al., 2017; Zhang et al., 2017b).

At the same time, RNAi has been widely used to investigate gene function in insects and has been especially employed to silence vital genes in $N$. lugens and other insects through the suppression of gene expression by injecting dsRNA or singlestranded RNA (siRNA) (Belles, 2010; Wang et al., 2012; Kola et al., 2015; Liu et al., 2015; Joga et al., 2016). Sustained and effective RNAi expressing dsRNA in the host plant or transgenemediated RNAi developed to decrease gene expression at the same time will be very useful for pest control (Baum et al., 2007; Mao et al., 2007; Swevers et al., 2013; Zhu, 2013; Jiang et al., 2016; Yu et al., 2016; Gillet et al., 2017). TRE has become an important target in pest management and control, and new and effective TRE inhibitor products with practical significance as pesticides are being developed (Tang et al., 2012, 2017). Therefore, there maybe two potential ways to control agriculture pests, one is development and application of effective trehalase inhibitors, and the other is plant produced sustained and effective dsTRE or dsRNA's of other important genes over time.

\section{ETHICS STATEMENT}

All applicable international, national, and/or institutional guidelines for the care and use of animals were followed.

\section{AUTHOR CONTRIBUTIONS}

Conceived and designed the experiments: LZ, SW, MZ, and BT. Performed the experiments and analyzed the data: LZ, LQ, HY, and HW. Contributed reagents/materials/analysis tools: LZ, MZ, SW, and BT. Wrote the paper: LQ, LZ, and BT. 


\section{ACKNOWLEDGMENTS}

We thank Dr. Hongxing Xu (Zhejiang Academy of Agricultural Sciences, Hangzhou, Zhejiang, China) and Dr. N. Senthil

\section{REFERENCES}

Arakane, Y., Dixit, R., Begum, K., Par, K, Y., Specht, C. A., Merzendorfer, $\mathrm{H}$., et al. (2009). Analysis of functions of the chitin deacetylase gene family in Tribolium castaneum. Insect Biochem. Mol. Biol. 39, 355-365. doi: 10.1016/j.ibmb.2009.02.002

Bansal, R., Mian, M. A., Mittapalli, O., and Michel, A. P. (2013). Molecular characterization and expression analysis of soluble trehalase gene in Aphis glycines, a migratory pest of soybean. Bull. Entomol. Res. 103, 286-295. doi: $10.1017 /$ S0007485312000697

Baum, J. A., Bogaert, T., Clinton, W., Heck, G. R., Feldmann, P., Ilagan, O., et al. (2007). Control of coleopteran insect pests through RNA interference. Nat. Biotechnol. 25, 1322-1326. doi: 10.1038/nbt1359

Becker, A., Schlöder, P., Steele, J. E., and Wegener, G. (1996). The regulation of trehalose metabolism in insects. Experientia 52, 433-439. doi: 10.1007/BF01919312

Belles, X. (2010). Beyond Drosophila: RNAi in vivo and functional genomics in insects. Аnnu. Rev. Entomol. 55, 111-128. doi: 10.1146/annurev-ento-112408-085301

Bieli, D., Kanca, O., Gohl, D., Denes, A., Schedl, P., Affolter, M., et al. (2015). The Drosophila melanogaster mutants ap ${ }^{\text {blot }}$ and ap ${ }^{\text {Xasta }}$ affect an essential apterous wing enhancer. G3 5, 1129-1143. doi: 10.1534/g3.115.017707

Casares, F., and Mann, R. S. (2000). A dual role for homothorax in inhibiting wing blade development and specifying proximal wing identities in Drosophila. Development 127, 1499-1508.

Chen, J., Tang, B., Chen, H. X., Yao, Q., Huang, X. F., Chen, J., et al. (2010a). Different functions of the insect soluble and membrane-bound trehalase genes in chitin biosynthesis revealed by RNA Interference. PLOS ONE 5:e10133. doi: 10.1371/journal.pone.0010133

Chen, X. F., Tian, H. G., Zou, L. Z., Tang, B., Hu, J., and Zhang, W. Q. (2008). Disruption of Spodoptera exigua larval development by silencing chitin synthase gene A with RNA interference. Bull. Entomol. Res. 98, 613-619. doi: $10.1017 /$ S0007485308005932

Chen, J., Zhang, D. W., Yao, Q., Zhang, J. Q., Dong, X. L., Tian, H. G., et al. (2010b). Feeding-based RNA interference of a trehalose phosphate synthase gene in the brown planthopper, Nilaparvata lugens. Insect Mol. Biol. 19, 777-786. doi: 10.1111/j.1365-2583.2010.01038.x

Deng, H. M., Li, Y., Zhang, J. L., Liu, L., and Feng, Q. L. (2016). Analysis of expression and chitin-binding activity of the wing disc cuticle protein BmWCP4 in the silkworm, Bombyx mori. Insect Sci. 23, 782-790. doi: 10.1111/1744-7917.12231

Diaz-Benjumea, F. J., and Cohen, S. M. (1993). Interactions between dorsal and ventral cells in the imaginal disc directs wing development in Drosophila. Cell 75, 741-752. doi: 10.1016/0092-8674(93)90494-B

Elbein, A. D., Pan, Y. T., Pastuszak, I., and Carroll, D. (2003). New insights on trehalose: a multifunctional molecule. Glycobiology 13, 17-27. doi: 10.1093/glycob/cwg047

Fasano, L., Roder, L., Core, N., Alexandre, E., Vola, C., Jacq, B., et al. (1991). The teashirt gene is required for the development of Drosophila embryonic trunk segments and encodes a protein with widely spaced zinc finger motifs. Cell 64, 63-79. doi: 10.1016/0092-8674(91)90209-H

Ge, L. Q., Zhao, K. F., Huang, L. J., and Wu, J. C. (2011). The effects of triazophos on the trehalose content, trehalase activity and their gene expression in the brown planthopper Nilaparvata lugens (Stål) (Hemiptera: Delphacidae). Pest. Biochem. Physiol. 100, 172-181. doi: 10.1016/j.pestbp.2011. 03.007

Gillet, F. X., Garcia, R. A., Macedo, L. L. P., Albuquerque, E. V. S., Silva, M. C. M., and Grossi-de-Sa, M. F. (2017). Investigating engineered ribonucleoprotein particles to improve oral RNAi delivery in crop insect pests. Front. Physiol. 8:256. doi: 10.3389/fphys.2017.00256
Kumar (Mizoram University, Aizawl, Mizoram, India) for their kind help. This work was supported by the National Natural Science Foundation of China (Grant No. 31371996 and 31672081).
Jiang, S., Wu, H., Liu, H., Zheng, J., Lin, Y., and Chen, H. (2016). The overexpression of insect endogenous small RNAs in transgenic rice inhibits growth and delays pupation of striped stem borer (Chilo suppressalis). Pest. Manag. Sci. 73, 1453-1461. doi: 10.1002/ps.4477

Joga, M. R., Zotti, M. J., Smagghe, G., and Christiaens, O. (2016). RNAi efficiency, systemic properties, and novel delivery methods for pest insect control: what we know so far. Front. Physiol. 7:553. doi: 10.3389/fphys.2016.00553

Kamei, Y., Hasegawa, Y., Niimi, T., Yamashita, O., and Yaginuma, T. (2011). Trehalase-2 protein contributes to trehalase activity enhanced by diapause hormone in developing ovaries of the silkworm, Bombyx mori. J. Insect Physiol. 57, 608-613. doi: 10.1016/j.jinsphys.2010.10.001

Kikuta, S., Hagiwara-Komoda, Y., Noda, H., and Kikawada, T. (2012). A novel member of the trehalose transporter family functions as an $\mathrm{h}(+)$-dependent trehalosetransporter in the reabsorption of trehalose in malpighian tubules. Front. Physiol. 3:290. doi: 10.3389/fphys.2012.00290

Klein, T., Couso, J. P., and Martinez Arias, A. (1998). Wing development and specification of dorsal cell fates in the absence of apterous in Drosophila. Curr. Biol. 8, 417-420. doi: 10.1016/S0960-9822(98)70162-9

Kola, V. S., Renuka, P., Madhav, M. S., and Mangrauthia, S. K. (2015). Key enzymes and proteins of crop insects as candidate for RNAi based gene silencing. Front. Physiol. 6:119. doi: 10.3389/fphys.2015.00119

Lee, J. H., Mori, H., Nishimoto, M., Okuyama, M., Kim, D., Wongchawalit, J., et al. (2007). Molecular cloning of cDNA for trehalase from the European honeybee, Apis mellifera $L$ and its heterologous expression in Pichia pastoris. Biosci. Biotechnol. Biochem. 71, 2256-2265. doi: 10.1271/bbb.70239

Leyva, A., Quintana, A., Sánchez, M., and Rodríguez, E. N. (2008). Cremata $\mathrm{J}$ and Sánchez J-C. rapid and sensitive anthrone-sulfuric acid assay in microplate format to quantify carbohydrate in biopharmaceutical products: method development and validation. Biologicals 36, 134-141. doi: 10.1016/j.biologicals.2007.09.001

Li, T. C., Chen, J., Fan, X. B., Chen, W. W., and Zhang, W. Q. (2017). MicroRNA and dsRNA targeting chitin synthase a reveal a great potential for pest management of the hemipteran insect Nilaparvata lugens. Pest. Manag. Sci. 73, 1529-1537. doi: 10.1002/ps.4492

Lin, X. D., Yao, Y., Jin, M., and Li, Q. (2014). Characterization of the Distalless gene homologure, NIDll, the brown planthopper, Nilaparvata lugens (Stål). Gene 535, 112-118. doi: 10.1016/j.gene.2013.11.056

Liu, S., Ding, Z., Zhang, C., Yang, B., and Liu, Z. (2010). Gene knockdown by intro-thoracic injection of double-stranded RNA in the brown planthopper, Nilaparvata lugens. Insect Biochem. Mol. Biol. 40, 666-671. doi: 10.1016/j.ibmb.2010.06.007

Liu, S., Liang, Q. M., Zhou, W. W., Jiang, Y. D., Zhu, Q. Z., Yu, H., et al. (2015). RNA interference of NADPH-cytochrome P450 reductase of the rice brown planthopper, Nilaparvata lugens, increases susceptibility to insecticides. Pest. Manag. Sci. 71, 32-39. doi: 10.1002/ps. 3760

Livak, K. J., and Schmittgen, T. D. (2001). Analysis of relative gene expression data using real-time quantitative PCR and the $2-\Delta \Delta$ CT method. Methods 25 , 402-408. doi: 10.1006/meth.2001.1262

Mao, Y. B., Cai, W. J., Wang, J. W., Hong, G. J., Tao, X. Y., Wang, L. J., et al. (2007) Silencing a cotton bollworm P450 monooxygenase gene by plant-mediated RNAi impairs larval tolerance of gossypol. Nat. Biotechnol. 25, 1307-1313. doi: $10.1038 /$ nbt1352

Milán, M., and Cohen, S. M. (2000). Temporal regulation of apterous activity during development of the Drosophila wing. Development 127, 3069-3078.

Mitsumasu, K., Azuma, M., Niimi, T., Yamashita, O., and Yaginuma, T. (2005). Membrane-penetrating trehalase from silkworm Bombyxmori. molecular cloning and localization in larval midgut. Insect Mol. Biol. 14, 501-508. doi: 10.1111/j.1365-2583.2005.00581.x

Niwa, N., Akimoto-Kato, A., Niimi, T., Tojo, K., Machida, R., and Hayashi, S. (2010). Evolutionary origin of the insect wing via 
integration of two developmental modules. Evol. Dev. 12, 168-176. doi: 10.1111/j.1525-142X.2010.00402.x

Pechmann, M., Khadjeh, S., Turetzek, N., McGregor, A. P., Damen, W. G., and Prpic, N. M. (2011). Novel function of Distal-less as a gap gene during spider segmentation. PLoS Genet. 7:e1002342. doi: 10.1371/journal.pgen.1002342

Plavicki, J., Mader, S., Pueschel, E., Peebles, P., and Boekhoff-Falk, G. (2012). Homeobox gene distal-less is required for neuronal differentiation and neurite outgrowth in the Drosophila olfactory system. Proc. Natl. Acad. Sci. U.S.A. 109, 1578-1583. doi: 10.1073/pnas.1016741109

Ramesh Kumar, D., Saravana Kumar, P., Gandhi, M. R., Al-Dhabi, N. A., Paulraj, M. G., and Ignacimuthu, S. (2016). Delivery of chitosan/dsRNA nanoparticles for silencing of wing development vestigial (vg) gene in Aedes aegypti mosquitoes. Int J. Biol. Macromol. 86, 89-95. doi: 10.1016/j.ijbiomac.2016.01.030

Shi, J. F., Xu, Q. Y., Sun, Q. K., Meng, Q. W., Mu, L. L., Guo, W. C., and Li, G. Q. (2016). Physiological roles of trehalose in Leptinotarsa larvae revealed by RNA interference of trehalose-6-phosphate synthase and trehalase genes. Insect Biochem. Mol. Biol. 77, 52-68. doi: 10.1016/j.ibmb.2016.07.012

Shi, Z. K., Liu, X. J., Xu, Q. Y., Qin, Z., Wang, S., Zhang, F., et al. (2016). Two novel soluble trehalase genes cloned from Harmonia axyridis and regulation of the enzyme in a rapid changing temperature. Comp. Biochem. Physiol. B 198, 10-18. doi: 10.1016/j.cbpb.2016.03.002

Shukla, E., Thorat, L. J., Nath, B. B., and Gaikwad, S. M. (2015). Insect trehalase: physiological significance and potential applications. Glycobiology 25, 357-367. doi: $10.1093 /$ glycob/cwu125

Soanes, K. H., MacKay, J. O., Core, N., Heslip, T., Kerridge, S., and Bell, J. B. (2001). Identification of a regulatory allele of teashirt (tsh) in Drosophila melanogaster that affects wing hinge development. an adult-specific tsh enhancer in Drosophila. Mech. Dev. 105, 145-151. doi: 10.1016/S0925-4773(01)00397-5

Stevens, M. E., and Bryant, P.J. (1985). Apparent genetic complexity generated by developmental thresholds: the apterous locus in Drosophila melanogaster. Genetics 110, 281-297.

Sunwoo, J. B., Kim, S., Yang, L., Naik, T., Higuchi, D. A., Rubenstein, J. L., et al. (2008). Distal-less homeobox transcription factors regulate development and maturation of natural killer cells. Proc. Natl. Acad. Sci. U.S.A. 105, 10877-10882. doi: 10.1073/pnas.0805205105

Swevers, L., Vanden Broeck, J., and Smagghe, G. (2013). The possible impact of persistent virus infection on the function of the RNAi machinery ininsects: a hypothesis. Front. Physiol. 4:319. doi: 10.3389/fphys.2013.00319

Tan, Y., Xiao, L., Sun, Y., Zhao, J., Bai, L., and Xiao, Y. (2014). Molecular characterization of soluble and membrane-bound trehalases in the cotton mirid bug, Apolygus lucorum. Arch. Insect Biochem. Physiol. 86, 107-121. doi: 10.1002/arch.21166

Tang, B., Chen, J., Yao, Q., Pan, Z. Q., Xu, W. H., Wang, S. G., et al. (2010). Characterization of a trehalose-6-phosphate synthase gene from Spodoptera exigua and its function identification through RNA interference. J. Insect Physiol. 56, 813-821. doi: 10.1016/j.jinsphys.2010.02.009

Tang, B., Chen, X. F., Liu, Y., Tian, H. G., Liu, J., Hu, J., et al. (2008). Characterization and expression patterns of a membrane-bound trehalase from Spodoptera exigua. BMC Mol. Biol. 9:51. doi: 10.1186/1471-2199-9-51

Tang, B., Qin, Z., Shi, Z. K., Wang, S., Guo, X. J., Wang, S. G., et al. (2014). Trehalase in Harmonia axyridis (Coleoptera: Coccinellidae): effects on beetle locomotory activity and the correlation with trehalose metabolism under starvation conditions. Appl. Entomol. Zool. 49, 255-264. doi: 10.1007/s13355-014-0244-4

Tang, B., Wei, P., Chen, J., Wang, S. G., and Zhang, W. Q. (2012). Progress in gene features and functions of insect trehalases. Acta Entomol. Sin. 55, 1315-1321. doi: 10.16380/j.kcxb.2012.11.008

Tang, B., Wei, P., Zhao, L. N., Shi, Z. K., Shen, Q. D., Yang, M. M., et al. (2016). Knockdown of five trehalase genes using RNA interference regulates the gene expression of the chitin biosynthesis pathways in Tribolium castaneum. BMC Biotechnol. 16:67. doi: 10.1186/s12896-016-0297-2

Tang, B., Yang, M., Shen, Q., Xu, Y. X., Wang, H. J., Wang, S. G., et al. (2017). Suppressing the activity of trehalase with validamycin disrupts the trehalose and chitin biosynthesis pathways in the rice brown planthopper, Nilaparvata lugens. Pest. Biochem. Physiol. 137, 81-90. doi: 10.1016/j.pestbp.2016.10.003

Tatun, N., Singtripop, T., and Sakurai, S. (2008a). Dual control of midgut trehalase activity by 20 -hydroxyecdysone and an inhibitory factor in the bamboo borer Omhisa fuscidentalis Hampson. J. Insect Physiol. 54, 351-357. doi: 10.1016/j.jinsphys.2007.10.006

Tatun, N., Singtripop, T., Tungjitwitayakul, J., and Sakurai, S. (2008b). Regulation of soluble and membrane-bound trehalase activity and expression of the enzyme in the larval midgut of the bamboo borer Omphisa fuscidentalis. Insect Biochem. Mol. Biol. 38, 788-795. doi: 10.1016/j.ibmb.2008.05.003

Thompson, S. N. (2003). Trehalose - the insect 'blood' sugar. Adv. Insect Physiol. 31, 203-285. doi: 10.1016/S0065-2806(03)31004-5

Wang, J. D., Wu, M., Wang, B. J., and Han, Z. J. (2013). Comparison of the RNA interference effects triggered by dsRNA and siRNA in Tribolium castameum. Pest. Manag. Sci. 69, 781-786. doi: 10.1002/ps.3432

Wang, J., He, W. B., Su, Y. L., Bing, X. L., and Liu, S. S. (2014). Molecular characterization of soluble and membrane-bound trehalases of the whitefly, Bemisia tabaci. Arch. Insect Biochem. Physiol. 85, 216-233. doi: 10.1002/arch.21155

Wang, Y., Fan, H. W., Huang, H. J., Xue, J., Wu, W. J., Bao, Y. Y., et al. (2012). Chitin synthase 1 gene and its two alternative splicing variants from two sap-sucking insects, Nilaparvata lugens and Laodelphax striatellus (Hemiptera: Delphacidae). Insect Biochem. Mol. Biol. 42, 637-646. doi: 10.1016/j.ibmb.2012.04.009

Williams, J. A., Paddock, S. W., and Carroll, S. B. (1993). Pattern formation in a secondary field: a hierarchy of regulatory genes subdivides the developing Drosophila wing disc into discrete subregions. Development 117, 571-584.

$\mathrm{Wu}$, J., and Cohen, S. M. (2002). Repression of Teashirt marks the initiation of wing development. Development 129, 2411-2418.

Xi, Y., Pan, P. L., and Zhang, C. X. (2015a). The $\beta$-N-acetylhexosaminidase gene family in the brown planthopper, Nilaparvata lugens. Insect Mol. Biol. 24, 601-610. doi: 10.1111/imb.12187

Xi, Y., Pan, P. L., Ye, Y. X., Yu, B., Xu, H. J., and Zhang, C. X. (2015b). Chitinaselike gene family in the brown planthopper, Nilaparvata lugens. Insect Mol. Biol. 24, 29-40. doi: 10.1111/imb.12133

Xi, Y., Pan, P. L., Ye, Y. X., Yu, B., and Zhang, C. X. (2014). Chitin deacetylase family genes in the brown planthopper, Nilaparvata lugens (Hemiptera: Delphacidae). Insect Mol. Biol. 23, 695-705. doi: 10.1111/imb.12113

Xue, J., Zhang, X. Q., Xu, H. J., Fan, H. W., Huang, H. J., Ma, X. F. et al. (2013). Molecular characterization of the flightin gene in the wing-dimorphic planthopper, Nilaparvata lugens, and its evolution in Pancrustacea. Insect Biochem. Mol. Biol. 43, 433-443. doi: 10.1016/j.ibmb.2013.02.006

Xue, J., Zhou, X., Zhang, C. X., Yu, L. L., Fan, H. W., Wang, Z., et al. (2014). Genomes of the rice pest brown planthopper and its endosymbionts reveal complex complementary contributions for host adaptation. Genome Biol. 15, 521. doi: 10.1186/s13059-014-0521-0

Yang, M. M., Zhao, L. N., Shen, Q. D., Xie, G. Q., Wang, S. G., and Tang, B. (2017). Knockdown of two trehalose-6-phosphate synthases severely affects chitin metabolism gene expression in the brown planthopper Nilaparvata lugens. Pest. Manag. Sci. 73, 206-216. doi: 10.1002/ps.4287

Yasugi, T., Yamada, T., and Nishimura, T. (2017). Adaptation to dietary conditions by trehalose metabolism in Drosophila. Sci. Rep. 7, 1619. doi: 10.1038/s41598-017-01754-9

Yu, X. D., Liu, Z. C., Huang, S. L., Chen, Z. Q., Sun, Y. W., Duan, P. F., et al. (2016). RNAi-mediated plant protection against aphids. Pest. Manag. Sci. 72, 1090-1098. doi: 10.1002/ps.4258

Zhang, L., Wang, H. J., Chen, J. Y., Shen, Q. D., Wang, S. G., and Xu, H. X., et al. (2017a). Glycogen phosphorylase and glycogen synthase: gene cloning and expression analysis reveal their role in trehalose metabolism in the Brown planthopper, Nilaparvata lugens Stål (Hemiptera: Delphacidae). J. Insect Sci. 17, 1-11. doi: 10.1093/jisesa/iex015

Zhang, L., Zhu, S. C., Zheng, H., Shen, Q. D., Wang, S. G., and Tang, B. (2017b). Regulatory function of trehalase genes on chitin metabolism in the cuticle of Nilaparvata lugens. Sci. Agric. Sin. 50, 1047-1056. doi: 10.3864/j.issn.0578-1752.2017.06.006

Zhang, Q., Lu, D. H., Pu, J., Wu, M., and Han, Z. J. (2012). Cloning and RNA interference effects of trehalase genes in Laodelphax striatellus (Homoptera: Delphacidae). Acta Entomol. Sin. 55, 911-920. doi: 10.16380/j.kcxb.2012.08.002

Zhang, W. Q., Chen, X. F., Tang, B., Tian, H. G., Chen, J., and Yao, Q. (2011). Insect chitin biosynthesis and its regulation. Chin. J. Appl. Entomol. 48, 475-479. doi: 10.1016/j.ejcb.2011.04.014 
Zhao, L. N., Yang, M. M., Shen, Q. D., Shi, Z. K., Wang, S. G., and Tang, B. (2016). Functional characterization of three trehalase genes regulating the chitin metabolism pathway in rice brown planthopper using RNA interference. Sci. Rep. 6, 27841-27854. doi: 10.1038/srep 27841

Zhu, K. Y. (2013). RNA interference: a powerful tool in entomological research and a novel approach for insect pest management. Insect Sci. 20, 1-3. doi: 10.1111/1744-7917.12006

Zhu, K. Y., Merzendorfer, H., Zhang, W. Q., Zhang, J. Z., and Muthukrishnan, S. (2016). Biosynthesis, turnover, and functions of chitin in insects. Annu. Rev. Entomol. 61, 177-196. doi: 10.1146/annurev-ento-010715-0 23933

Zhu, Q. S., Arakane, Y., Beeman, R. W., Kramer, K. J., and Muthukrishnan, S. (2008). Functional specialization among insect chitinase family genes revealed by RNA interference. Proc. Natl. Acad. Sci. U.S.A. 105, 6650-6655. doi: $10.1073 /$ pnas. 0800739105

Conflict of Interest Statement: The authors declare that the research was conducted in the absence of any commercial or financial relationships that could be construed as a potential conflict of interest.

Copyright (c) 2017 Zhang, Qiu, Yang, Wang, Zhou, Wang and Tang. This is an open-access article distributed under the terms of the Creative Commons Attribution License (CC BY). The use, distribution or reproduction in other forums is permitted, provided the original author(s) or licensor are credited and that the original publication in this journal is cited, in accordance with accepted academic practice. No use, distribution or reproduction is permitted which does not comply with these terms. 